\title{
Structural Investigation of Crystalline Host Phosphor Cadmium Tellurite Systems
}

\author{
Rosli Hussin ${ }^{1, *}, \mathrm{Ng}$ Siang Leong ${ }^{1}$ and Nur Shahira Alias ${ }^{1}$ \\ ${ }^{1}$ Phosphor Research Unit, Jabatan Fizik, Fakulti Sains, Universiti Teknologi Malaysia, 81310 UTM Skudai, Johor. \\ *Author to whom correspondence should be addressed; E-mail: rbh@dfiz2.fs.utm.my
}

Received: 31 October 2008, Revised: 15 April 2009

Online Publication: 27 May 2009

http://dx.doi.org/10.11113/mjfas.v5n1.283

\section{ABSTRACT}

Generally, the luminescent properties of phosphors are strongly dependent on the crystal structure of the host materials. Finding a stable crystal structure, high physical and chemical stability of crystalline matrix is still a critical step to obtain rare-earth ions or transition metal ions-doped persistent phosphor with excellent properties. The glassceramic materials based on cadmium tellurite developed for stable host phosphor is reported in this paper. The structure of $\mathrm{TeO}_{2}$ and $\mathrm{CdO}-\mathrm{TeO}_{2}$ system has been investigated by means of FT-Raman, Infrared (IR) spectroscopy and x-ray diffraction (XRD) spectroscopies. Cadmium tellurite system were prepared with the compositions of XCdO-(1x) $\mathrm{TeO}_{2}$ with $0.1 \leq \mathrm{x} \leq 0.5$ in percent molar ratio, doped with $1 \% \mathrm{~mol}_{\mathrm{MnO}_{2}}$, using solid state method. The $\mathrm{x}$-ray diffraction measurement results showed that the phase in the cadmium tellurite system matched quite well with the standard ICDD files, indicating that the phases present in this sample appeared to be a phase of $\alpha-\mathrm{TeO}_{4}$ trigional bipyramid (tbp), $\mathrm{CdTe}_{2} \mathrm{O}_{5}$ and $\mathrm{CdTeO}_{3}$. The Raman and Infrared spectra show that the structures are mainly builds by $\mathrm{TeO}_{4}$ (tbp) groups, $\mathrm{TeO}_{3+1}$ trigional pyramid (tp) and $\mathrm{TeO}_{3}(\mathrm{tp})$, while $\mathrm{Cd}^{2+}$ ions play as network modifiers. As addition concentration of $\mathrm{CdO}$ increases, $\mathrm{TeO}_{4}$ (tbp) groups progressively change polymerized framework structure in $\mathrm{TeO}_{4}$ (tbp) into $\mathrm{TeO}_{3+1}$ trigional pyramid (tp) and $\mathrm{TeO}_{3}(\mathrm{tp})$. On the contrary, the addition of $1 \mathrm{~mol} \% \mathrm{MnO}_{2}$ into the sample did not giving any effect on the structural of the final samples.

| Host phosphor I X-ray diffraction I Infrared spectroscopy I Raman spectroscopy I Tellurite glasses |

\section{Introduction}

Photoluminescent material with long afterglow is a kind of energy storage material that can absorb both the ultraviolet (UV) and visible lights from the sunlight and gradually release the energy in the darkness at a certain wavelength. These phosphors have been studied for a long time [1]. The properties of photoresistance and chemical stability, great brightness, long duration, no radiation and environmental capability result in their wide applications in many fields such as safety indication, lighting in emergency, instrument in automobile, luminous paint and optical devices.

Till now, the most efficient long afterglow phosphors are still based on alkaline-earth aluminates [2], silicates [3] and sulfides [4]. The persistent luminescence of $\mathrm{ZnS}$-based materials-doped $\mathrm{Cu}$ or $\mathrm{Mn}$ materials is not bright enough, and the afterglow time is short, and the materials are sensitive to the humidity. Sulfide will 
absorb the moisture from the surrounding environment to form sulfate that causes the destruction of sulfide lattice, and thus the material no longer shows long afterglow. As for the practical applications, even the alkaline earth aluminates have been found too sensitive to moisture despite their luminescence properties being much superior conventional $\mathrm{ZnS}: \mathrm{Cu}$ materials. Silicates are suitable hosts of phosphors because of their high physical and chemical stability, especially their excellent water-resistant property but need relatively high firing temperatures.

Almost all good inorganic phosphors consist of a crystalline "host material" in which small amounts of certain impurities, the "activators" are dissolved. The activators are primarily responsible for the luminescence. Other impurities, the "co-activators" are necessary in some cases to dissolve the activator impurities into the host crystal [1]. Generally, the luminescent properties of phosphors are strongly dependent on the crystal structure of the host materials. Finding a right matrix is still a critical step to obtain rare-earth ions or transition metal ionsdoped phosphor with excellent properties [5-7].

In recent years, many new phosphors based on different hosts are actively investigated, but the progress in developing the persistant phosphors with excellent lighting properties is still slow due to the lack of the suaitable host and mechanisms of long afterglow [7]. Tellurite in general are good candidates for many technological applications. These materials have a low melting temperature $\left(\sim 800-950{ }^{\circ} \mathrm{C}\right)$, are not hygroscopic, have low glass transformation temperature $\left(\leq 400^{\circ} \mathrm{C}\right)$, high dielectric constant, high thermal expansion coefficient, and high optical transmission in the infrared region [8-13]. Moreover, these glasses are typically of high density, and high refractive index [14]. These properties, due to the high polarisability of $\mathrm{Te}^{4+}$ ions (with a solitary electron pair $5 \mathrm{~s}^{2}$ ), can be even more enhanced by means of the incorporation of other heavy metals oxides that can be easily polarized (e.g. $\left.\mathrm{Bi}^{3+}, \mathrm{Pb}^{2+}\right)$ or with empty d orbital $\left(\mathrm{Ti}^{4+}, \mathrm{Nb}^{5+}\right)$. Apart from these special optical properties, other advantages of such material will be promising candidates for luminescent hosts materials since they have stable crystal structure, high physical and chemical stability and their ability to host different rare earth or transition metal ions.

Transition metal ions eg. $\mathrm{Mn}^{2+}$, have been widely used in luminescent materials. The emission can be either in green or red region depending on the host matrix because of the sensitivity of the $\mathrm{d}-\mathrm{d}$ transition in $\mathrm{Mn}^{2+}$ to the crystal field [15]. However, to the best of our knowledge, the luminescence properties $\mathrm{Mn}^{2+}$ in cadmium tellurite system has not yet been reported as a long-lasting phosphor materials so far. Cadmium tellurite matrices systems are attractive host materials for the study of development of advanced phosphors due to low melting point, high thermal stability and good rare-earth or transition metal ions solubility.

The aim of this work is to report the suitable crystalline phase composition and its structure present in cadmium tellurite system which can be used as stable host lattices phosphor through x-ray diffraction (XRD), infrared (IR) and Raman spectroscopic studies. It is important to find stable host in which different emission wavelengths can be obtained by doped with different concentration of $\mathrm{Mn}^{2+}$ ions. So the tellurite based materials with long afterglow properties with new crystalline structures are necessary to be developed.

\section{Experimental Procedures}

\section{Sample Preparation}

Cadmium tellurite samples were prepared with the compositions of $\mathrm{xCdO}-(1-\mathrm{x}) \mathrm{TeO}_{2}$ doped with $1 \mathrm{~mol} \%$ $\mathrm{MnO}_{2}$, where $\mathrm{x}=0.1$ to 0.5 in molar ratio, using the conventional solid state method. All chemicals used were reagent grade of $\mathrm{MnO}_{2}$ (Sigma), $\mathrm{CdCO}_{3}$ and $\mathrm{TeO}_{2}$ (Aldrich). The stoichiometric compositions of the batch materials $(10 \mathrm{~g})$ were thoroughly mixed and milled in an agate mortar and then heated in a alumina crucible at temperatures in the range of $900-950^{\circ} \mathrm{C}$ for about half an hour in an electrically furnace in air atmosphere. The 
furnace was switch off and the samples was leftout until it cool at room temperature before removed from the furnace.

\section{Characterization}

The structure of the prepared samples was analyzed by means of X-ray diffraction measurements (XRD), using powders. The XRD measurements were carried out with $\mathrm{CuK}_{\alpha}$ radiation at room temperature using Siemens Diffractometer D5000, equipped with diffraction software analysis. The diffraction spectral data were collected at constant $(2 \theta)$ steps of $0.04^{\circ}$, where $2 \theta$ from 10 to $80^{\circ}$, and dwell of $4 \mathrm{~s}$. The d-spacings obtained were compared with those in the literature in an attempt to identify the crystal phases formed. As reference the latest database of ICDD (International Center for Diffraction Data, ICDD) was also used.

The infrared (IR) spectra have been recorded using a Perkin-Elmer Spectrum One FT-IR spectrometer from 2000 to $400 \mathrm{~cm}^{-1}$ at intervals of $4 \mathrm{~cm}^{-1}$. There were no characteristic absorption bands in the range of $4000-$ $1300 \mathrm{~cm}^{-1}$ for the samples. Hence the spectra are presented for the region of $1200-400 \mathrm{~cm}^{-1}$ in this work. Measurements were carried out on dispersed in pressed $\mathrm{KBr}$ pellets containing the same weight of the powder samples to enable us to roughly compare the relative intensities of the bands.

The Raman spectra were measured with a Perkin-Elmer Spectrum GX spectrometer in the spectral range $100-1200 \mathrm{~cm}^{-1}$. The sample was excited with an argon ion laser with power of about $200 \mathrm{~mW}$. The spectrum was observed in the quasi-back scattered mode. The digital intensity data were recorded at intervals of $4 \mathrm{~cm}^{-1}$ and the spectral resolution was about $4 \mathrm{~cm}^{-1}$.

\section{Results}

\section{XRD Patterns}

Fig. 1 shows the XRD patterns from all of the samples as formed in $\mathrm{xCdO}-(1-\mathrm{x}) \mathrm{TeO}_{2}$ system. All the obtained samples were fully crystalline. The diffraction patterns of the crystalline phases formed on cooling were identified as crystalline paratellurite $\alpha-\mathrm{TeO}_{2}$ (ICDD: 42-1365), $\mathrm{CdTe}_{2} \mathrm{O}_{5}$ (ICDD: 24-0169), $\mathrm{CdTeO}_{3}$ (ICDD: 771906), as summarized in Table 1.

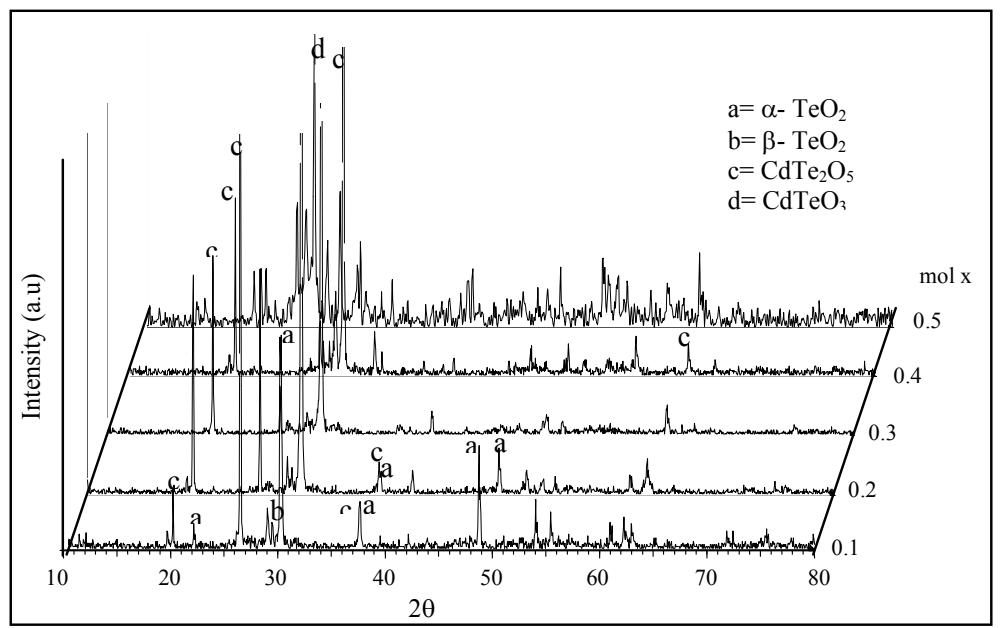

Figure 1: X-ray diffraction (XRD) patterns of $\mathrm{xCdO}-(1-\mathrm{x}) \mathrm{TeO}_{2}$ system, with $0.1 \leq \mathrm{x} \leq 0.5$. 
Table 1: Composition of the samples $\mathrm{xCdO}-(1-\mathrm{x}) \mathrm{TeO}_{2}$ and it identify crystalline phase.

\begin{tabular}{lll}
\hline \multicolumn{2}{l}{ Composition } \\
\hline $\mathrm{CdO}$ & $\mathrm{TeO}_{2}$ & Phase \\
\hline 0.1 & 0.9 & $\alpha-\mathrm{TeO}_{2}(\mathrm{~m}), \mathrm{CdTe}_{2} \mathrm{O}_{5}(\mathrm{mn})$ \\
\hline 0.2 & 0.8 & $\alpha-\mathrm{TeO}_{2}(\mathrm{~m})^{*}, \mathrm{CdTe}_{2} \mathrm{O}_{5}(\mathrm{mn})$ \\
\hline 0.3 & 0.4 & $\mathrm{CdTe}_{2} \mathrm{O}_{5}(\mathrm{~m}), \mathrm{CdTeO}_{3}(\mathrm{mn})$ \\
\hline 0.4 & 0.6 & $\mathrm{CdTe}_{2} \mathrm{O}_{5}(\mathrm{~m}), \mathrm{CdTeO}_{3}(\mathrm{mn})$ \\
\hline 0.5 & 0.5 & $\mathrm{CdTeO}_{3}(\mathrm{~m}), \mathrm{CdTe}_{2} \mathrm{O}_{5}(\mathrm{mn})$ \\
\hline \multicolumn{4}{r}{ Note: $\mathrm{m}-$ major phase, mn- minor phase, } \\
\end{tabular}

\section{Raman Spectra}

Raman spectra of the $\alpha, \beta$ and $\gamma-\mathrm{TeO}_{2}$ powder, along with $\mathrm{xCdO}-(1-\mathrm{x}) \mathrm{TeO}_{2}$ samples are presented in Fig. 2. Raman vibration frequencies are summeried in Table 2. Raman spectra of $10 \mathrm{CdO}-90 \mathrm{TeO}_{2}$-glass is rather similar to $\alpha-\mathrm{TeO}_{2}$ data including the typical broadening observed in glasses, consist of major bands in the $600-800 \mathrm{~cm}$ $\mathrm{cm}^{-1}$ range and a broad band around $490 \mathrm{~cm} \mathrm{~cm}^{-1}$. The typical broadening of the vibration bands due to the glassy state is observed. The Raman spectrum of the glass matrix presents six bands at: 748, 626, 533, 406, 288 and 140 $\mathrm{cm}^{-1}$ (Fig. 1).

The $\alpha-\mathrm{TeO}_{2}$ spectrum presented in Fig. 2 is dominated by two bands at 647 and $392 \mathrm{~cm}^{-1}$. Smaller features are observed at $158,175,339,591,718,721$ and $767 \mathrm{~cm}^{-1}$. Maximum positions were measured with $\pm 5 \mathrm{~cm}^{-1}$ accuracy. $\alpha-\mathrm{TeO}_{2}$ belongs to the $\mathrm{D}_{4}^{4}$ space group and the Raman bands are assigned following the work by Pine and Dresselhaus [16]. In this way the bands with the largest amplitudes at 392 and $647 \mathrm{~cm}^{-1}$ are assigned to the $v_{2}\left(\mathrm{~A}_{1}\right)=\left(v_{\mathrm{s}} \mathrm{TeO}_{2 \mathrm{ax}}\right)$ and $v_{1}\left(\mathrm{~A}_{1}\right)=v_{\mathrm{s}} \mathrm{TeO}_{2 \mathrm{eq}}$ vibrational mode. $\delta_{1}, \delta_{2}, v_{a s}\left(\mathrm{Terminal}\right.$ Oxygen, $\left.\mathrm{TeO}_{\mathrm{ax}}\right)$ and $v_{a s}\left(\mathrm{TeO}_{2 \mathrm{eq}}\right)$ modes are related to the smaller bands at $591,718,721$ and $767 \mathrm{~cm}^{-1}$, respectively. The structure of $\alpha-\mathrm{TeO}_{2}$ is built of $\left(\mathrm{TeO}_{4}\right)$ trigonal bipyramids (tbp) connected at the vertices and the two bands at 392 and $647 \mathrm{~cm}^{-1}$ have been assumed to be due to this structure. Spectra for samples $\mathrm{x}=0.1,0.2$ and $\mathrm{x}=0.3$ in the larger $\mathrm{TeO}_{2}$ content part of the phases in Fig. 2 are assumed to be an envelope of the crystalline $\alpha-\mathrm{TeO}_{2}$ spectrum, assigned to vibrations of $\left(\mathrm{TeO}_{4}\right)$ species. As we go further from $\mathrm{x}=0.3$ to $\mathrm{x}=0.4$ part in the samples, these bands diminish in amplitude at the expense of an increase in amplitude of the component at $724 \mathrm{~cm}^{-1}$. This last band is assigned to $\left(\mathrm{TeO}_{3}\right)$ trigonal pyramids (tp) and is due to the breakdown of the initially fully polymerized structure occurring with the addition of cadmium oxide. From sample $\mathrm{x}=0.4$ and 0.5 , the addition of $\mathrm{CdO}$ is followed by the appearance of a completely new band, in the $724 \mathrm{~cm}^{-1}$ region which is the same as that for $\mathrm{TeO}_{3}$ bonds in $\mathrm{Na}_{2} \mathrm{TeO}_{3}$ groups [17] and $\mathrm{ZnTeO}_{3}[18,19]$. This Raman spectra is similar with $\beta-\mathrm{TeO}_{2}$.

The Raman spectra were also exhibited two main peaks at around $\sim 650$ and $\sim 730 \mathrm{~cm}^{-1}$. The relative intensity of the $730 \mathrm{~cm}^{-1}$ peak due to $\mathrm{TeO} 3+1$ units against the $650 \mathrm{~cm}^{-1}$ peak intensity due to the $\mathrm{TeO} 4$ tbp decreases with $\mathrm{CdO}$ content. From these results the addition of an intermediate oxide is assumed to develop the $\mathrm{TeO} 3$ entities. The Raman bands around 650 and $730 \mathrm{~cm}^{-1}$ are assigned to stretching vibrations in $\mathrm{TeO}_{4}$ and $\mathrm{TeO}_{3}$ and/ or $\mathrm{TeO}_{3+1}$ groups, respectively. The increase in intensity observed for the $730 \mathrm{~cm}^{-1}$ band with $\mathrm{CdO}$ concentration. The dominant three-dimensional network structures in the glassy mixture of $\left(10 \mathrm{CdO}-90 \mathrm{TeO}_{2}\right)$ are triagonal pyramidal $\mathrm{TeO}_{3}$ with minor features of short range of distorted tbp $\mathrm{TeO}_{4}$ in which a tbp $\mathrm{TeO}_{4}$ unit is linked together by $\mathrm{Te}_{\mathrm{ax}}-\mathrm{O}-\mathrm{Te}_{\mathrm{eq}}$ bridges to form a primary bridged tetrahedral unit of $\mathrm{Te}_{2} \mathrm{O}_{7}\left(\mathrm{TeO}_{3+1}\right)$, leading to a structure of infinite chain. Therefore, $10 \mathrm{CdO}-90 \mathrm{TeO}_{2}$ sample experience structural changes from $\mathrm{TeO}_{4}$ (tbp); $\mathrm{Te}_{2} \mathrm{O}_{7}$ $\left(\mathrm{TeO}_{3+1}\right)$ or $\mathrm{TeO}_{3}$ when doped with $\mathrm{CdO}$. 


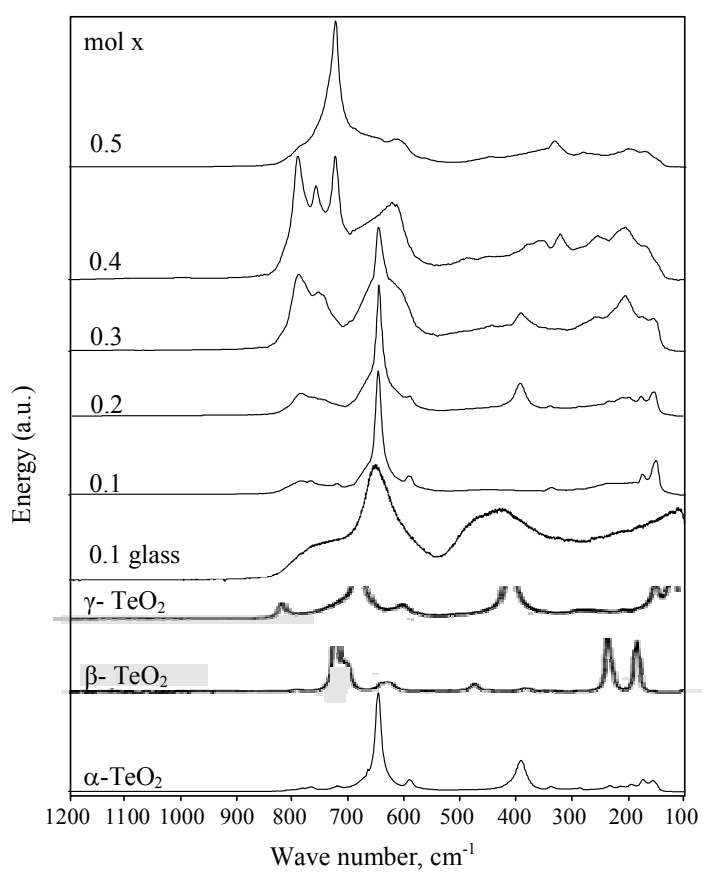

Figure 2: Raman spectra of the different polymorph of $\alpha, \beta, \gamma-\mathrm{TeO}_{2}$ and samples $\mathrm{xCdO}-(1-\mathrm{x}) \mathrm{TeO}_{2}$ system, with $0.1 \leq \mathrm{x} \leq 0.5$.

Table 2: Raman characteristic frequencies of crystalline $\mathrm{TeO}_{2}$ and $\mathrm{xCdO}-(1-\mathrm{x}) \mathrm{TeO}_{2}$ system, with $0.1 \leq \mathrm{x} \leq 0.5$.

\begin{tabular}{lcccccccc}
\hline & $\delta(\mathrm{Te}-\mathrm{O}-\mathrm{Te})$ & $\delta\left(\mathrm{TeO}_{3}{ }^{2-}\right)$ & $\mathrm{v}_{\mathrm{s}}(\mathrm{Te}-\mathrm{O}-\mathrm{Te})$ & $\mathrm{v}_{\mathrm{as}} \mathrm{TeO}_{4}$ & $\mathrm{v}_{\mathrm{s} 1} \mathrm{TeO}_{4}$ & $\mathrm{v}_{\mathrm{s}}\left(\mathrm{Te}-\mathrm{O}^{-}\right)$ & $\mathrm{v}_{\mathrm{s} 2} \mathrm{TeO}_{4}$ & $\mathrm{v}_{\mathrm{s}}\left(\mathrm{TeO}_{3}{ }^{2-}\right)$ \\
\hline$\alpha-\mathrm{TeO}_{2}$ & $158,175,339$ & $392^{*}$ & 591 & $647^{*}$ & 721 & 767 & \\
\hline$\beta-\mathrm{TeO}_{2}$ & 234,336 & & 450 & 595 & 673 & $740^{*}$ & & \\
\hline$\gamma-\mathrm{TeO}_{2}$ & & 426 & & $680^{*}$ & & 820 & \\
\hline $\mathrm{x}=0.1$ & 151,175, & 339 & - & 594 & $647^{*}$ & 722 & 767 & 785 \\
\hline 0.2 & 155,175, & 339 & 393 & 592 & $648^{*}$ & & 765 & 788 \\
\hline 0.3 & $156,177,207$ & & 392,445 & 611 & $647^{*}$ & & 754 & $789^{*}$ \\
\hline 0.4 & 169,207 & $257,323,357$ & 490 & & $623^{*}$ & $724^{*}$ & 759 & $791^{*}$ \\
\hline 0.5 & $156,175,203$ & $262,283,336$ & 454 & 613 & 629 & $724^{*}$ & & 793 \\
\hline \multicolumn{7}{c}{ Note: Sh- shoulder, ${ }^{*}$ - main peak (sharp and highest) }
\end{tabular}

The Raman frequencies of crystalline $\mathrm{TeO}_{2}$ observed around 150 to $350 \mathrm{~cm}^{-1}$ are due to the oscillations of the metal cation ( $\mathrm{Te}$ ) in its oxygen cavities of the $\mathrm{TeO}_{4}$ tetrahedra [19]. These bands are a characteristic feature of tetragonal $\mathrm{TeO}_{2}$ [20-21]. The bands around 188, 219-223, 266-270, and 343-350 $\mathrm{cm}^{-1}$ observed in the spectra of samples containing up to $50 \mathrm{~mol} \%$ (Fig. 2) correspond to the vibrational modes of the $\mathrm{TeO}_{4}$ tetrahedra [21]. The great similarity between these spectra and the spectrum of crystalline $\mathrm{TeO}_{2}$ suggests that the short range structure of these sample is a ordered version of tetragonal $\mathrm{TeO}_{2}$ with $\mathrm{TeO}_{4}$ trigonal bipyramids structural units [13]. The Raman spectra also shown that the sample does not have either free $\mathrm{OH}$ or hydrogen bonded $\mathrm{OH}$ groups, due to the absence of stretching (3150-3500 $\left.\mathrm{cm}^{-1}\right)$ and bending modes $\left(1650-1750 \mathrm{~cm}^{-1}\right)$ of hydroxyl group [23,24]. In order to complete this Raman structural approach, we have also undertaken an investigation by infrared spectroscopy. 


\section{FT-IR spectra}

The FT-IR spectra of of $\mathrm{xCdO}-(1-\mathrm{x}) \mathrm{TeO}_{2}$ system, with $0.1 \leq \mathrm{x} \leq 0.5$ and crystalline $\alpha-\mathrm{TeO}_{2}$ the present investigation are shown in Fig. 3. The characteristic IR frequencies of crystalline $\mathrm{TeO}_{2}$ and the samples are summarized in Table 3. It can be seen that each spectrum consists of a major band in the range of $600-800 \mathrm{~cm}^{-1}$. This band was mainly assigned to vibrations due to tellurium-oxygen polyhedra in line with assignments by [25]. The spectrum of crystalline $\mathrm{TeO}_{2}$ shows two net peaks at 780 and $675 \mathrm{~cm}^{-1}$ and a shoulder at about $635 \mathrm{~cm}^{-1}$. These bands correspond respectively to the symmetric axial $v_{2}\left(\mathrm{~A}_{1}\right)=\left(v_{\mathrm{s}} \mathrm{TeO}_{2 \mathrm{ax}}\right)=635 \mathrm{~cm}^{-1}$, vibration of the continuous networks composed of $\mathrm{TeO}_{4}$ tetragonal bipyramids (tbp), and the symmetric equatorial $v_{1}\left(A_{1}\right)=$ $v_{\mathrm{s}} \mathrm{TeO}_{2 \mathrm{eq}}=780 \mathrm{~cm}^{-1}$ (sharp) vibrational modes of the $\mathrm{TeO}_{4}$ tetrahedral units [26]. The band around $675\left(\mathrm{v}_{6}\left(\mathrm{~B}_{2}\right)=\right.$ $\left.\mathrm{v}_{\mathrm{as}} \mathrm{TeO}_{2 \mathrm{ax}}\right)$ and $714 \mathrm{~cm}^{-1}\left(\mathrm{v}_{8}\left(\mathrm{~B}_{1}\right)=\mathrm{v}_{\mathrm{as}} \mathrm{TeO}_{2 \mathrm{eq}}\right)$ is assigned to antisymmetric vibrations of Te-O-Te linkages constructed by two unequivalent Te-O bonds [26].

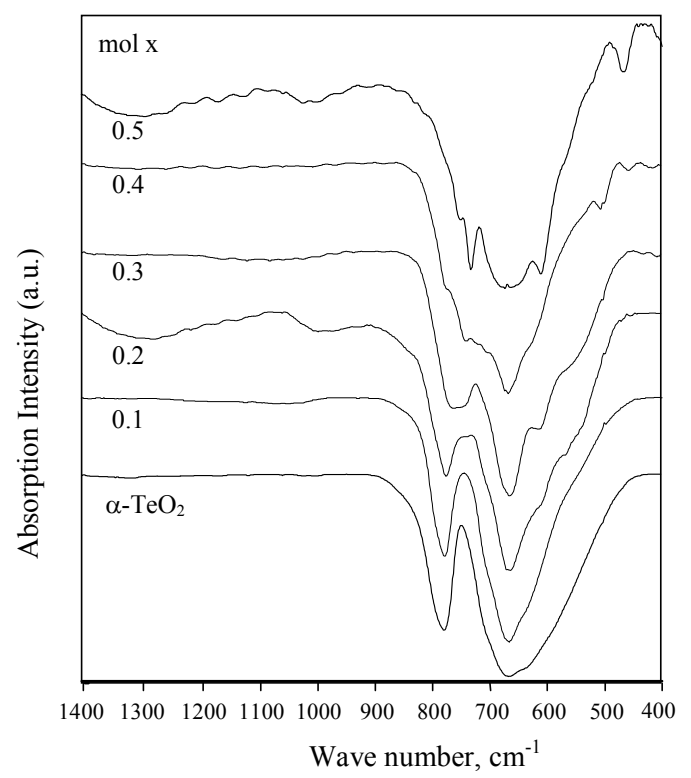

Figure 3: FTIR spectra of $\mathrm{xCdO}-(1-\mathrm{x}) \mathrm{TeO}_{4}$, with $0.1 \leq \mathrm{x} \leq 0.5$ doped $1 \mathrm{~mol} \% \mathrm{MnO}_{2}$ and $\alpha-\mathrm{TeO}_{2}$ crystalline samples.

Table 3: IR characteristic frequencies of crystalline $\mathrm{TeO}_{2}$ and $\mathrm{xCdO}-(1-\mathrm{x}) \mathrm{TeO}_{2}$ system, with $0.1 \leq \mathrm{x} \leq 0$.

\begin{tabular}{|l|l|l|l|l|l|l|}
\hline & & $U_{s} \mathrm{TeO}_{2 \mathrm{ax}}$ & $\mathrm{Uas}_{\mathrm{TeO}} \mathrm{Tea}_{2 \mathrm{ax}}$ & $\mathrm{U}_{\mathrm{as}} \mathrm{TeO}_{2 \mathrm{eq}}$ & $\mathrm{Us}_{\mathrm{s}} \mathrm{TeO}_{3}$ & $\mathrm{Us}_{\mathrm{s}} \mathrm{TeO}_{2 \mathrm{eq}}$ \\
\hline$\alpha-\mathrm{TeO}_{2}$ & & $635 \mathrm{sh}$ & 675 & 714 & & 780 \\
\hline $\mathrm{x}=0.1$ & $545 \mathrm{sh}$ & $647 \mathrm{sh}$ & 663 & 695 & & 774 \\
\hline 0.2 & $565 \mathrm{sh}$ & $615 \mathrm{sh}$ & 660 & 694 & & 772 \\
\hline 0.3 & $558 \mathrm{sh}$ & 607 & 660 & & 750,768 & \\
\hline 0.4 & 505 & 637 & 664 & & 737 & 770 \\
\hline 0.5 & $464,548 \mathrm{sh}$ & 610 & 660 & 729 & $749,765 \mathrm{sh}$ & \\
\hline
\end{tabular}

Note: Sh- shoulder 


\section{Discussion}

At ambient conditions, $\mathrm{TeO}_{2}$ is known to exist in the two polymorphous forms, paratellurite, $\alpha-\mathrm{TeO}_{2}[19-21]$ and tellurite, $\beta-\mathrm{TeO}_{2}$ [26], the constitution of $\mathrm{TeO}_{2}$ system was always unambiguously related to one of them, namely, to the former structure. In those units, the two Te-O bonds have lengths of about $1.87 \AA$ and form the angle $103^{\circ}$, which is rather close to the atomic arrangement in the isolated $\mathrm{TeO}_{2}$ molecule [26]. In the lattice, the molecules are packed so that every atom of Te has the two new neighboring oxygen atoms separated from him for about $2.12 \AA$. Thus, with the four nearest oxygen atoms, each Te atom builds a $\mathrm{TeO}_{4}$ polyhedron in view of a trigonal bipyramid, called disphenoid. Its 'axis' is formed by the two long Te-O bonds, whereas the equatorial plane includes the two short Te-O molecular bonds and the $5 \mathrm{~s}^{2}$ lone electron pair of Te. These short bonds are called 'equatorial', and the long ones 'axial'. According to the recent first principles calculations [25], the bond orders have values of 1.7 and 0.3 for those two bonds, respectively. Therefore, the first of them $(1.87 \AA)$ can be classified as mainly covalent, whereas the second one $(2.12 \AA)$ most likely has largely electrostatic nature, and result from the dipole-dipole intermolecular interactions. In both structures, tellurium atoms have four neighbouring oxygen atoms and the basic structural unit is a $\mathrm{TeO}_{4}$ disphenoid, or if we take into account the $5 \mathrm{~s}^{2}$ lone pair of tellurium atoms (E), a distorted $\mathrm{TeO}_{4} \mathrm{E}$ bipyramid. In this bipyramid, the two equatorial oxygen atoms are separated from $\mathrm{Te}$ by distances shorter than the sum of the covalent radii of $\mathrm{O}\left(0.73 \mathrm{~A}^{\circ}\right)$ and of $\mathrm{Te}$ $\left(1.35 \mathrm{~A}^{\circ}\right)$, and the two axial oxygen atoms by distances longer than that value (Fig. 4).

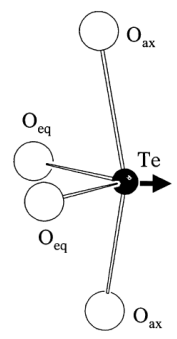

Figure 4: Basic structural unit for the $\mathrm{TeO}_{4}$ present in $\alpha$ - and $\beta-\mathrm{TeO}_{2}$. [ 17,23]

The local structure around Te atoms has been classified into five groups based on the structural units present in tellurite crystals as illustrated in Fig. 5. These are (1) $\mathrm{TeO}_{3}$ type which consists of an isolated $\mathrm{TeO}_{3}$ type and a terminal $\mathrm{TeO}_{3}$ type, (2) $\mathrm{TeO}_{3+1}$ type and (3) $\mathrm{TeO}_{4}$ type which consists of an $\alpha-\mathrm{TeO}_{2}$ type and a $\beta-\mathrm{TeO}_{2}$ type. An isolated $\mathrm{TeO}_{3}$ type means that the $\mathrm{TeO}_{3}$ tp structural unit is present as a free anion; the terminal $\mathrm{TeO}_{3}$ type means that the $\mathrm{TeO}_{3}$ tp has one corner which is connected with a neighboring $\mathrm{TeO}_{n}$ polyhedron; the $\mathrm{TeO}_{3+1}$ type means that the $\mathrm{TeO}_{3}$ tp has an additional $\mathrm{O}$ atom at a remote distance from 0.22 to $0.25 \mathrm{~nm}$. Furthermore, the $\alpha-\mathrm{TeO}_{2}$ type contains $\mathrm{TeO}_{4}$ tbp structural units which are connected by sharing their corners, and the $\beta-\mathrm{TeO}_{2}$ type contains $\mathrm{Te}_{2} \mathrm{O}_{6}$ units consisting of two edge-shared $\mathrm{TeO}_{4}$ tbps. Three structural $\mathrm{TeO} n$ entities have been reported (Fig.1): first a TeO4 somewhat trigonal bipyramid (tbp) group with two axial and two equatorial oxygen atoms (the third equatorial position of the $s p^{3} d$ hybrid orbitals is occupied by the lone pair); second, a TeO3+1 asymmetric polyhedron in which one Te-O axial bond shortens while the other elongates; third, a TeO3 trigonal pyramid (tp) with three short $\mathrm{Te}-\mathrm{O}$ distances. $\mathrm{TeO} 4$ and $\mathrm{TeO} 3$ entities look like the tellurium oxygenated environment existing, respectively, in the crystal of $\alpha-\mathrm{TeO} 2$ and $\mathrm{ZnTeO} 3$. Therefore these crystalline phases were used as reference samples. In $\alpha-\mathrm{TeO} 2$ the distorded tbp $\mathrm{TeO} 4$ exhibits two axial Te-Oax bonds $\left(2.08 \mathrm{~A}^{\circ}\right)$ and two equatorial Te-Oeq bonds $\left(1.90 \mathrm{~A}^{\circ}\right)$, while the Te environment in $\mathrm{ZnTeO} 3$ is a tp TeO3 with a mean Te$\mathrm{O}$ distance equal to $1.876 \mathrm{~A}^{\circ}$. 
(a) $\mathrm{TeO}_{4}$ type
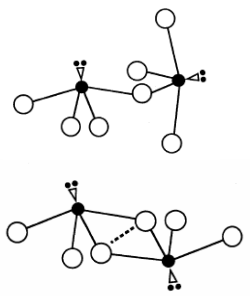

(b) $\mathrm{TeO}_{3+1}$ type

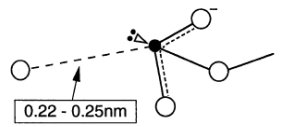

(c) $\mathrm{TeO}_{3}$ type<smiles>C[C@H]1O[C@@H]([O-])O1</smiles>

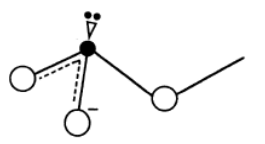

$\alpha-\mathrm{TeO}_{2}$

- corner sharing

- $\mathrm{TeO}_{3}{ }^{2-}$ ion

- trigonal bipyramid (tbp)

$\beta-\mathrm{TeO}_{2}$

- edge sharing

$\mathrm{Te}_{2} \mathrm{O}_{7}{ }^{6-}$ ion $\left(\mathrm{TeO}_{3+1}\right)$

Bridged tetrahedral

Isolated

$-\mathrm{TeO}_{3}{ }^{2-}$ ion

-Triagonal pyramid (tp)

Terminal

$\mathrm{TeO}_{3}{ }^{2-}$ ion

Triagonal pyramid (tp)

Note: \begin{tabular}{ll|}
$0 \cdots . . . T e$ \\
$O \cdots . . .0$
\end{tabular}

Figure 5: Illustration of the structural models of $\mathrm{TeO}_{4}$ type. [23]

Conventionally, the $\alpha$ and $\beta-\mathrm{TeO}_{2}$ structures are described as frameworks of these $\mathrm{TeO}_{4}$ units, packed in such a way that each oxygen atom is coordinated to two tellurium atoms thus forming a highly asymmetric bridge Te- ${ }_{a x} \mathrm{O}_{\text {eq }}-\mathrm{Te}$ (Fig. 6(a) and (b)). In the $\alpha-\mathrm{TeO}_{2}$ structure, $\mathrm{TeO}_{4}$ units constitute, by sharing corners, the threedimensional network visualised in Fig. 6(a). In the $\beta-\mathrm{TeO}_{2}$ structure, they share, alternately, corners and edges and so constitute a two-dimensional network sheets in Fig. 6(b). The structures are regarded as consisting of symmetric Te-O-Te bridges in which bonds are chemically identical.

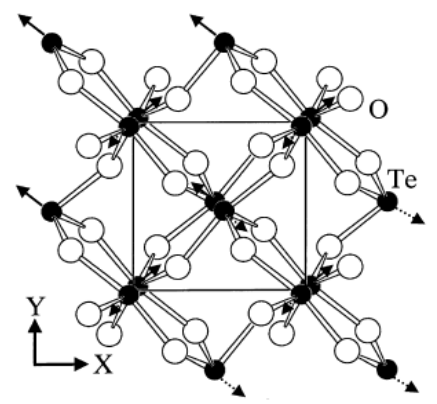

(a)

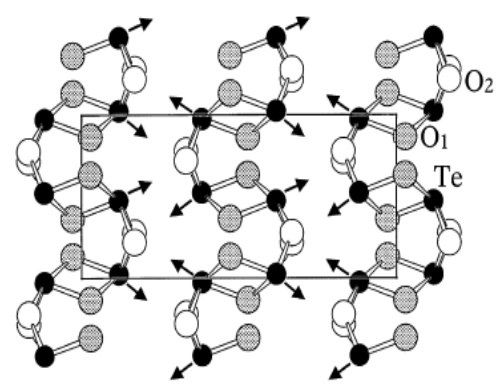

(b)

Figure 6: Structures of the different $\mathrm{TeO}_{2}$ crystalline polymorphs: (a) the xy projection of the $\alpha-\mathrm{TeO}_{2}$ lattice; corner sharing (b) the $\beta-\mathrm{TeO}_{2}$ lattice projection showing its layer structure, edge sharing. (arrows indicate the position of lone electron pairs of Te). (This figure is taken from Ref. [20])

In the paratellurite lattice $\left(\alpha-\mathrm{TeO}_{2}\right.$ structure), the $\mathrm{TeO}_{2}$ molecules frame the spiral-like tunnels so that the lone pairs of $\mathrm{Te}$-atoms are always oriented inside them, and two $\mathrm{TeO}_{4}$ neighbouring disphenoids are 
interconnected via a common corner without having common $\mathrm{O}-\mathrm{O}$ edges (Fig. 6(a)). The concept of the $\mathrm{TeO}_{4}$ disphenoids as its basic units suggests that the paratellurite lattice is the 3D-framework, made of the bent Te-OTe bridges considered as homologues to the $\mathrm{Si}-\mathrm{O}-\mathrm{Si}$ bridges in the quartz lattice. In this connection it is useful to recall some general features inherent for the Raman spectra of such lattices. The middle-frequency and the highest-frequency parts of the spectra are associated with the displacements of the oxygen atoms, and can be described in terms of localized stretching vibrations of the Te-O-Te bridges. The Raman intensity of the asymmetric $\mathrm{Te}-\mathrm{O}-\mathrm{Te}$ stretching vibrations (occupying the highest frequency range) is related to the difference in the electronic polarizability properties of the two bonds involved on the Te-O-Te bridge. Consequently, if the bonds are identical, those vibrations would have a vanishing intensity in the Raman spectra. Contrary to this, the symmetric Te-O-Te stretching vibrations lying in the middle-frequency part of the spectrum would produce the strongest lines.

The $\beta-\mathrm{TeO}_{2}$ lattice (tellurite) [26] is also made from the $\mathrm{TeO}_{4}$ disphenoids (Fig. 6(b)), but its constitution is essentially other. In contrast to $\alpha-\mathrm{TeO}_{2}$, the disphenoids in $\beta-\mathrm{TeO}_{2}$ are adjusted alternatively by their corners and edges, and the nearest atoms of $\mathrm{Te}$ are linked via two $\mathrm{Te}_{\mathrm{ax}}-\mathrm{O}_{\mathrm{eq}}-\mathrm{Te}$ bridges (which can be called double bridges [19-21]), thus framing a sharply pronounced anisotropic (layer) structure.

These studies have revealed two basic findings. First, pure $\mathrm{TeO}_{2}$ consists of $\mathrm{TeO}_{4}$ trigonal bipyramids (tbp) in which one equatorial site of the $\mathrm{sp}^{3} \mathrm{~d}$ hybrid orbitals is occupied by a lone pair of electrons and the other two equatorial and axial sites are occupied by oxygen atoms. Second, addition of $\mathrm{CdO}$ modifiers into the $\mathrm{TeO}_{2}$ network causes a change of the Te coordination polyhedron from $\mathrm{TeO}_{4}$ tbp to $\mathrm{TeO}_{3}$ trigonal pyramid (tp) in which one of the Te $\mathrm{sp}^{3}$ hybrid orbitals is occupied by a lone pair of electrons; this transformation causes also an increases in the number on non-bridging oxygen (NBO) atoms.

The basic structural unit of the tellurite glass is made up of a [TeO4] trigonal bipyramid (tbp) with one of the equatorial positions occupied by a lone pair of electrons. A network modifier/glass-former causes the change in coordination of $\mathrm{Te}$ atom from $\mathrm{TeO} 4$ tbp line structure of $\alpha-\mathrm{TeO}_{2}$ (tetragonal) and that of $\beta-\mathrm{TeO}_{2}$ (tetragonal) are different from each other.

The Raman spectra of the $\alpha$ - and $\beta-\mathrm{TeO}_{2}$ lattices (Fig. 2(a) and (b)) are clearly dominated by the strong high-frequency stretching vibrations, and have rather weak lines in the middle-frequency part. Thus, the presence of the largely covalent terminal $\mathrm{Te}-\mathrm{O}$ bond is unequivocally manifested there, whereas none of the lines in those spectra indicates the existence of $\mathrm{Te}-\mathrm{O}-\mathrm{Te}$ bridges made of such bonds. Therefore, from the objective spectrochemical point of view, the $\alpha$ - and $\beta-\mathrm{TeO}_{2}$ lattices cannot be considered as a classic framework, but rather as island-type ones, i.e. those built up from the quasi isolated $\mathrm{TeO}_{2}$ molecules whose synchronous vibrational are account for the high frequency strongest bands in Fig. 2(a) and (b).

The vibrational spectrum of inorganic solid materials could be studied on the basis of isolated and repeated structural units [19-27]. Therefore, the structural studies for triagonal bipyramid $\mathrm{TeO}_{4}{ }^{2-}(C 2 \mathrm{v})$ and bridged tetrahedral $\mathrm{TeO}_{3+1}$ have been found effective to characterize the structural features of tellurite system using Raman measurements comparable with infrared method [19-27]. Spectroscopic investigations have shown that $\mathrm{CdO}-\mathrm{TeO}_{2}$ systems are formed by a three-dimensional network composed of asymmetrical $\mathrm{TeO}_{4}$ trigonal bipyramids (tbps) when the $\mathrm{CdO}$ content is relatively low. An increase in the $\mathrm{CdO}$ concentration leads to the progressive formation of distorted $\mathrm{TeO}_{3}$ or $\mathrm{TeO}_{3+1}$ units (where the subscript " $3+1$ " indicates the existence of a longer bond compared to the three others, followed by the creation of regular trigonal $\mathrm{TeO}_{3}$ pyramids (tps) associated with non-bridging oxygen atoms (NBO). As known, tellurite glasses follow the pattern of crystalline $\alpha-\mathrm{TeO}_{2}$, which are formed by [ $\mathrm{TeO}_{4}$ ] groups as trigonal bipyramids (tbp) [21]. In tellurite glasses, such structural units can progressively form $\left[\mathrm{TeO}_{3+1}\right]$ and trigonal pyramids $\left[\mathrm{TeO}_{3}\right](\mathrm{tp})$ when the glass network becomes more open and non-bridging oxygens are created due to the incorporation of $\mathrm{CdO}$ ions. 


\section{Conclusion}

Cadmium tellurite in the system $\mathrm{CdO}-\mathrm{TeO}_{2}$ doped with $1 \mathrm{~mol} \% \mathrm{MnO}_{2}$ were prepared by solid state method. $\mathrm{XRD}$, IR and Raman spectroscopies have been used in order to approach the structure of $\mathrm{CdO}-\mathrm{TeO}_{2}$ system. The presence of CdO showed additional Raman bands at about $790 \mathrm{~cm}^{-1}$ apart from the normal bands for crystalline phase of tellurite. The addition of more $\mathrm{CdO}$ suppressed the creation of more $\mathrm{TeO}_{3}$ tp units. There established a trade of between $\mathrm{TeO}_{4}$ tbp and $\mathrm{TeO}_{3}$ tp units due to the presence of $\mathrm{CdTeO}_{3}$. The XRD patterns confirm $\mathrm{Cd}_{2} \mathrm{TeO}_{5}$ and $\mathrm{CdTeO}_{3}$ phase in the investigated system up to $40 \mathrm{~mol} \% \mathrm{CdO}$. The vibrational spectra evidenced that the main structural units are $\mathrm{Cd}_{2} \mathrm{TeO}_{5}$ and $\mathrm{CdTeO}_{3}$, followed same trand in XRD patterns. These glasses present characteristic tellurium atoms coordination changes, with the $\mathrm{CdO}$ content, from $\mathrm{TeO}_{4} \mathrm{E}$ through $\mathrm{TeO}_{3+1} \mathrm{E}$ to $\mathrm{TeO}_{3} \mathrm{E}$ units with NBO. Increasing the concentration of cadmium oxide, $\left(\mathrm{TeO}_{3}\right)$ units are produced as a result of depolimerization processes. $\mathrm{CdO}$ oxide transforms the tellurite network assuming to act as a network modifier. The addition of low concentrations $1 \% \mathrm{MnO}_{2}$ is insufficient to break the weak non-equivalent Te-O bond in the $\mathrm{TeO}_{4}$ building unit. Spectroscopic properties indicate that these system are potential hosts for presistent phosphor and the photoluminesce study of these material is in progress.

\section{Acknowledgments}

We would like to acknowledge the financial supports from Ministry of Science Technology and Inovation (MOSTI) under research grant Project Number: 03-01-06-SF0053, and the authors thank Ibnu Sina Institute, Department of Chemistry, Faculty of Science UTM and Faculty of Mechanical UTM for providing the Raman, FT-IR spectroscopies and XRD measurement facilities.

\section{References}

[1] G. Blasse, B.C. Grabmaier, Luminescent Materials, Springer, Berlin, 1994.

[2] E. Nakazawa and T. Mochida, Journal of Luminescence, $72 \& 74$ (1997) 236.

[3] Tuomas Aitasalo, Dariusz Hreniak, Jorma Holsa, Taneli Laamanen, Mika Lastusaari, Janne Niittykoski, Fabienne Pelle, Wieslaw Strek, Journal of Luminescence, 122\&123 (2007)110.

[4] M. Bredol, J. Merikhi, C. Ronda, Ber. Bunsen-Ges. Phys. Chem. Chem. Phys. 96 (1992) 1770.

[5] Y. Lin, C.W. Nan, X. Zhou, J. Wu, H. Wang, D. Chen, S. Xu, Mater. Chem. Phys. 82 (2003) 860.

[6] T. Aitasalo, P. Deren', J. Holsa, H. Jungner, J.C. Krupa, M. Lastusaari, J. Legendziewicz, J. Niittykoski, W. Strek, J. Solid State Chem. 171 (2003) 114.

[7] J. Holsa T. Aitasalo, H. Jungner, M. Lastusaari, J. Niittykoski, G. Spano, J. Alloys Comp. 374 (2004) 56.

[8] B.C. Sales, Mater. Res. Soc. Bull. 12 (1987) 32.

[9] F.L. Galeener and J.C. Mikkelsen Jr., Solid State Commun. 30 (1979) 505.

[10] S.W. Martin, Eur. J. Solid State Chem. 28 (1991) 163.

[11] D.R. Tallant, C. Nelson and J.A. Wilder, J. Phys. Chem. Glasses 27 (1986) 71.

[12] Y. Himei, Y. Miura, T. Nanba, A. Osaka, J. Non-Cryst. Solids 211 (1997) 64.

[13] R. Rolli, K. Gatterer, M. Wachtler, M. Bettinelli, A. Speghini, D. Ajo, Spectrochim. Acta A 57 (2001) 2009.

[14] M.J. Weber, J.D. Myers, D.H. Blackburn, J. Appl. Phys. 52 (1981) 2944.

[15] S.J. Choquette, J.C. Travis, D.L. Duewer, Proc. SPIE 3425 (1998) 102.

[16] A.S. Pine, G. Dresselhaus, Phys. Rev. B 5 (10) (1972) 4087.

[17] T. Sekiya, N. Mochida, A. Ohtsuka, M. Tonokawa, J. Non-Cryst. Solids 144 (1992) 128.

[18] H. Bü rger, K. Kneipp, H. Hobert, W. Vogel, V. Kozhukarov, S. Neov, J. Non-Cryst. Solids 151 (1992) 134.

[19] Nelson B.N., and Examos G.J., J. Chem. Phys. 71(1979)2739. 
[20] O. Noguera, T. Merle-Mejean, A.P. Mirgorodsky, M.B. Smirnov, P. Thomas, J.-C. Champarnaud-Mesjard, J. Non-Cryst. Solids 330 (2003) 50.

[21] Shaltout I., Tang Y., Braunstein R. and Abu-Elazm A. M., J. Phys. Chem. Solids 56,141 (1995).

[22] Peercy P. S. and Fritz, I. J., Phys. Rev. Left. 32, (1974). 466.

[23] S. Sakida, S. Hayakawa, T. Yoko, J. Non-Cryst. Solids 243 (1999) 1.

[24] J. C. Sabadel, P. Armand, P.-E. Lippens, D. Cachau-Herreillat, E. Philippot, J. Non-Cryst. Solids 244 (1999) 143.

[25] P.A. Thomas, J. Phys. C: Solid State Phys. 21 (1988) 4611.

[26] V.H. Beyer, Z. Kristallogr. 124 (1967) 228.

[27] O. Noguera, M. Smirnov, A.P. Mirgorodsky, T. Merle-Mejean, P. Thomas, J.C. Champarnaud-Mesjard, J. Non-Cryst. Solids 345\&346 (2004) 734. 